Supplement of The Cryosphere, 14, 1067-1081, 2020

https://doi.org/10.5194/tc-14-1067-2020-supplement

(C) Author(s) 2020. This work is distributed under

the Creative Commons Attribution 4.0 License.

(c) (1)

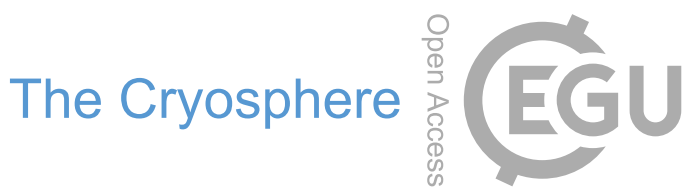

Supplement of

\title{
Ice island thinning: rates and model calibration with in situ observations from Baffin Bay, Nunavut
}

\author{
Anna J. Crawford et al. \\ Correspondence to: Anna J. Crawford (ajc44@st-andrews.ac.uk)
}

The copyright of individual parts of the supplement might differ from the CC BY 4.0 License. 


\section{Supplementary information}

\section{S1: Ice penetrating radar details}

\section{$\underline{\text { Stationary system: }}$}

The stationary ice penetrating radar (SIPR) receiver and transmitter were contained in two waterproof cases separated by $4.8 \mathrm{~m}$ and connected by $\sim 1 \mathrm{~m}$ lengths of 2 inch diameter PVC pipe which housed the antennas as well as a fiber-optic triggering cable. A microcontroller unit was programmed to operate as a timing engine to control both a power switch for daily measurements and a programmable micoUPS (micro-Uninterruptible Power Supply) to prevent potential power losses while the radar system is operating. Radar data as well as system health data were sent daily via the Iridium network (RoadBLOCK+ modem). The rest of the system comprises a small footprint computer and a digitizer along the same principles described by Mingo and Flowers (2010). The system was run by customized software developed by Blue System Integration Ltd (Vancouver, Canada). The system was programmed with a pulse repetition frequency of $128 \mathrm{~Hz}$ via the fiber oprtic triggering unit. The sampling rate was 125 megasamples per second and the system recorded 256 consecutive signal 'traces' that were collected and averaged ('stacked') to increase the signal to noise ratio (Hubbard and Glasser, 2005). The sIPR system and the weather station tripod were designed to 'float' with the melting ice surface. Stability was provided by sets of PVC conduit, drilled $\sim 5.5 \mathrm{~m}$ into the ice, and larger PVC sleeves that slid over the stakes and remained on the ice surface and to which the equipment was connected.

\section{Mobile system:}

Each measurement acquired by the $25 \mathrm{MHz}$ mobile IPR (mIPR) system was stacked 256 times in the IceRadar software program (v. 4.4.41b; Blue System Integration Ltd.). The mIPR oscilloscope digitizer waveform sampling interval was set to $250 \mathrm{MHz}$. A 'dewow' high-pass filter and a linear gain control were used to decrease noise and enhance reflections during post-processing in Radar Tools (release 0.4; Annan, 2009; Wilson, 2012, 2013). A Stolt (F-K) migration was applied to qualitatively assess the location of signal reflections over these sections which had large thickness gradients.

\section{References:}

Annan, A. P.: Electromagnetic principles of ground penetrating radar, in: Ground Penetrating Radar Theory and Applications, edited by: Jol, H., Elsevier, Oxford, UK. doi:10.1016/B978-0-444-53348-7.00001-6, 1-40, 2009.

Hubbard, B., and Glasser, N. F.: Field Techniques in Glaciology and Glacial Geomorphology, John Wiley \& Sons Ltd, West Sussex, England., 2005.

Mingo, L., and Flowers, G.: An integrated lightweight ice-penetrating radar system, J Glaciol, 56(198), 709-714, 2010.

Narod, B.B., and Clarke, G.K.C.: Miniature high-power impulse transmitter for radio-echo sounding. J Glaciol, 40(134), 190-194, 1994. 
Wilson, N.: Characterization and interpretation of polythermal structure in two subarctic glaciers, MSc thesis, University of British Columbia, Vancouver, BC., 241 pp., 2012.

Wilson, N.: Radar Tools. Software program, available at: http://doi.org/10.5281/zenodo.43972, 2013.

\section{S2: Image processing and polygon digitization error}

Custom Python (v. 2.7) scripts were used to convert the Level 1b SAR data to amplitude images in a Lambert Conformal Conic projection (WGS 1984 datum) with bilinear resampling using GDAL utility programs (www.gdal.org). The images were then stretched to improve contrast. The resulting geotif files were viewed in ArcMap (v. 10.2-10.5; ESRI, Redlands, California) and a polygon was digitized to represent Petermann Ice Island (PII)-A-1-f in each image. Digitization followed the 'polygon trimming' method of Crawford et al. (2018). An error assessment based on the work of Paul et al. (2013), Mueller et al. (2017) and Crawford et al. (2018) was conducted to determine the precision in manual polygon digitizing. The 'polygon trimming' workflow was conducted five times with at least 1 day between attempts for one pair of Fine-Quad RADARSAT-2 images (i.e., the polygon representing PII-A-1-f in the first image was rotated and trimmed to fit the ice island as captured in the second image). The coefficient of variation $(0.7 \%)$ of polygon area was calculated from the five fitted polygons as a measure of uncertainty in the digitized areal dimension.

References:

Crawford, A., Crocker, G., Mueller, D., Desjardins, L., Saper, R., and Carrieres, T.: The Canadian Ice Island Drift, Deterioration and Detection (CI2D3) Database, J Glaciol, 1-5, doi:10.1017/jog.2018.36, 2018.

Mueller, D., Copland, L., and Jeffries, M. O.: Changes in Canadian Arctic ice shelf extent since 1906, in: Arctic Ice Shelves and Ice Islands, edited by: Copland, L. and Mueller D., Springer, Dordrecht, The Netherlands, 109-148, 2017.

Paul, F., Barrand, N. E., Baumann, S., Berthier, E., Bolch, T., Casey, K., Frey, H., Joshi, S. P., Konovalov, V., Bris, R. L., Mölg, N., Nosenko, G., Nuth, C., Pope, A., Racoviteanu, A., Rastner, P., Raup, B., Scharrer, K., Steffen, S., and Winsvold, S.: On the accuracy of glacier outlines derived from remote-sensing data, Annals Glaciol, 54(63), 171-182, doi:10.3189/2013AoG63A296, 2013. 